\title{
A NOTE ON VACCINIUM BRASSII SLEUMER (ERICACEAE), RECORDING FILAMENTOUS WAX ON THE FLOWERS
}

\section{G. Argent ${ }^{\dagger} \&$ F. Christie}

\begin{abstract}
Routine identification of historical Vaccinium specimens at E revealed scurfy deposits on a specimen identified as Vaccinium brassii Sleumer. On examination with a scanning electron microscope, these scurfy deposits were found to be filamentous wax remarkably similar to that observed in Vaccinium ceraceum Argent. The disparity between the geographical locations of the two species is noted, together with the lack of molecular data on which to base insights into their evolutionary relationships.
\end{abstract}

Keywords. Ericaceae, New Guinea flora, Vaccinium, waxy deposits.

Received 5 March 2019 Accepted 19 August 2021 Published 23 September 2021

\section{Introduction}

Waxy deposits were first recorded in Vaccinium by Chu et al. (2017), who found them on the fruits of nine cultivars of $V$. corymbosum L. and $V$. ashei J.M.Reade grown in China. The first report of waxy deposits on a species from Southeast Asia was made by Argent (2018), who found them on the flowers of Vaccinium ceraceum Argent (Figures 1, 2).

A collection of Vaccinium, Woods 3039 (E), was made at Murray Pass in the Wharton Range, near Sidibamu village, Central District, Papua New Guinea, in 1968. Murray Pass is very close to the type locality of Vaccinium brassii Sleumer, and Woods 3039 keys directly to this species in Flora Malesiana (Sleumer, 1966-1967). Leonard Brass made the type collection of Vaccinium brassii in June 1933 at Murray Pass, Wharton Range, at $2840 \mathrm{~m}$ altitude (Brass 4695, lectotype NY; isolectotypes A, BO, BRI, L, US), during the first Archbold expedition (1933-1934) to Southeast Papua, now part of Papua New Guinea. A comparison of Woods 3039 with the description of Vaccinium brassii in the protologue, and with online images of the isolectotypes held at A, BRI and US, showed that it matches the type very closely.

Sleumer's accounts of the two varieties of Vaccinium brassii, namely $V$. brassii var. brassii and $V$. brassii var. madarum Sleumer, recorded both with pruinose fruit but described the corollas and calyces as essentially glabrous outside (Sleumer, 1942). Woods 3039 differs from these descriptions only by its distinctively scurfy flowers.

To view the detailed structure of the scurf on the flowers of Woods 3039 , the material was examined by scanning electron microscopy. 


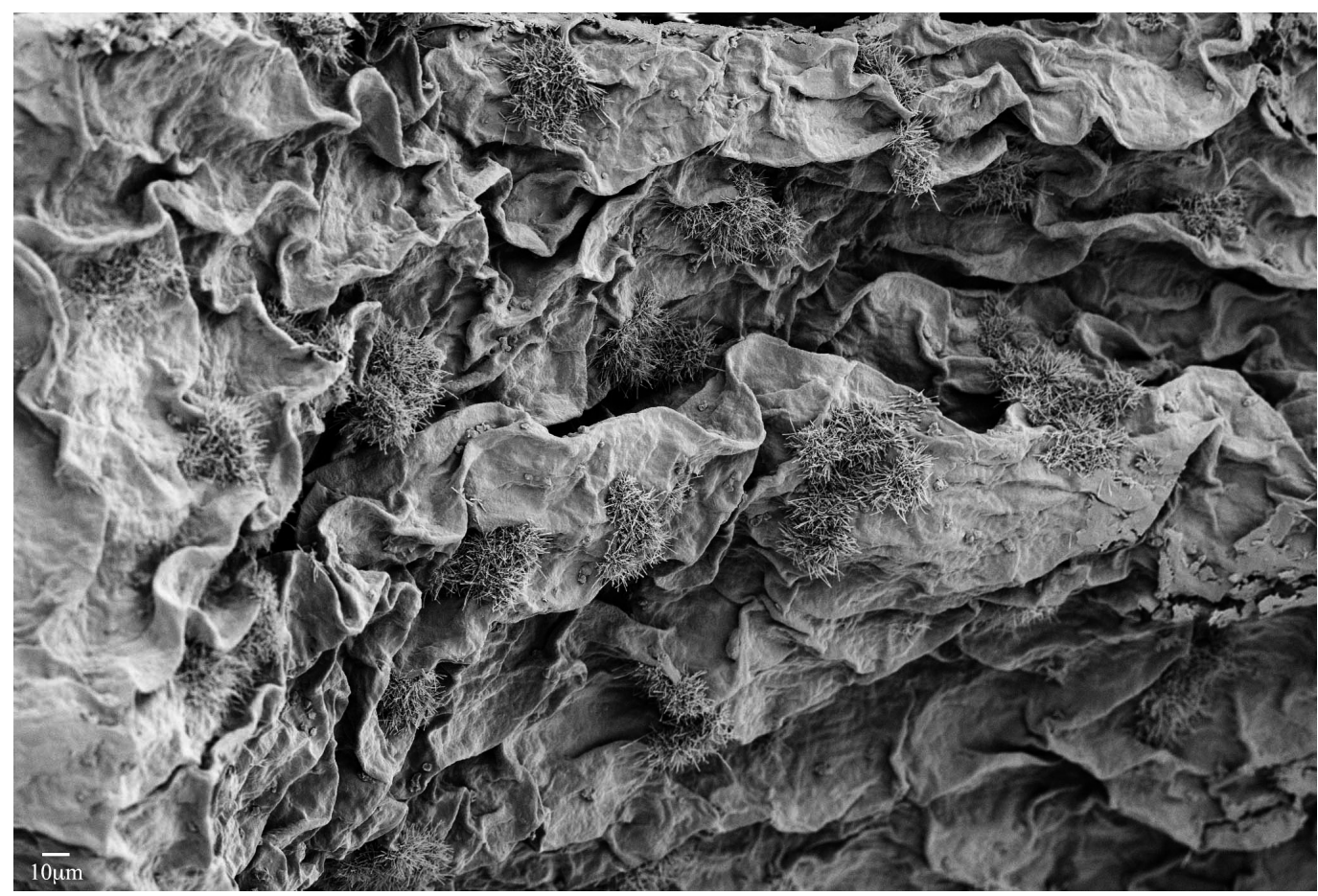

Figure 1. Waxy deposits on the surface of Vaccinium ceraceum [Kato et al. 23426 (E)]. Magnification: $\times 500$. Scanning electron micrograph: F. Christie. Reproduced from Argent (2018) with the permission of the Trustees of the Royal Botanic Garden Edinburgh.

\section{Materials and methods}

Herbarium material, specifically small fragments $\left(c .2-3 \mathrm{~mm}^{2}\right)$ of the corolla tube of Woods 3039 (E) (Vaccinium brassii), were mounted on aluminium stubs and coated in platinum (application time, 2 min) using a Quorum K575X sputter coater (Quorum, Laughton, UK). Images of the samples were obtained using a LEO Supra 55VP scanning electron microscope (Zeiss, Oberkochen, Germany). The waxy deposits observed on the surface were unstable in the heat of the 5-kV electron beam, making them difficult to focus on; however, it was possible to capture images of the structure by working quickly to minimise damage.

To verify that the wax deposits were not due to contamination, some of the material was boiled in detergent. This treatment is equivalent to making collections in alcohol by the Schweinfurth method.

\section{Results and discussion}

Here, we report the second record of remarkable tufts of filamentous wax on the flowers of Vaccinium, which adds to our knowledge of wax on the fruits of commercial blueberry varieties 


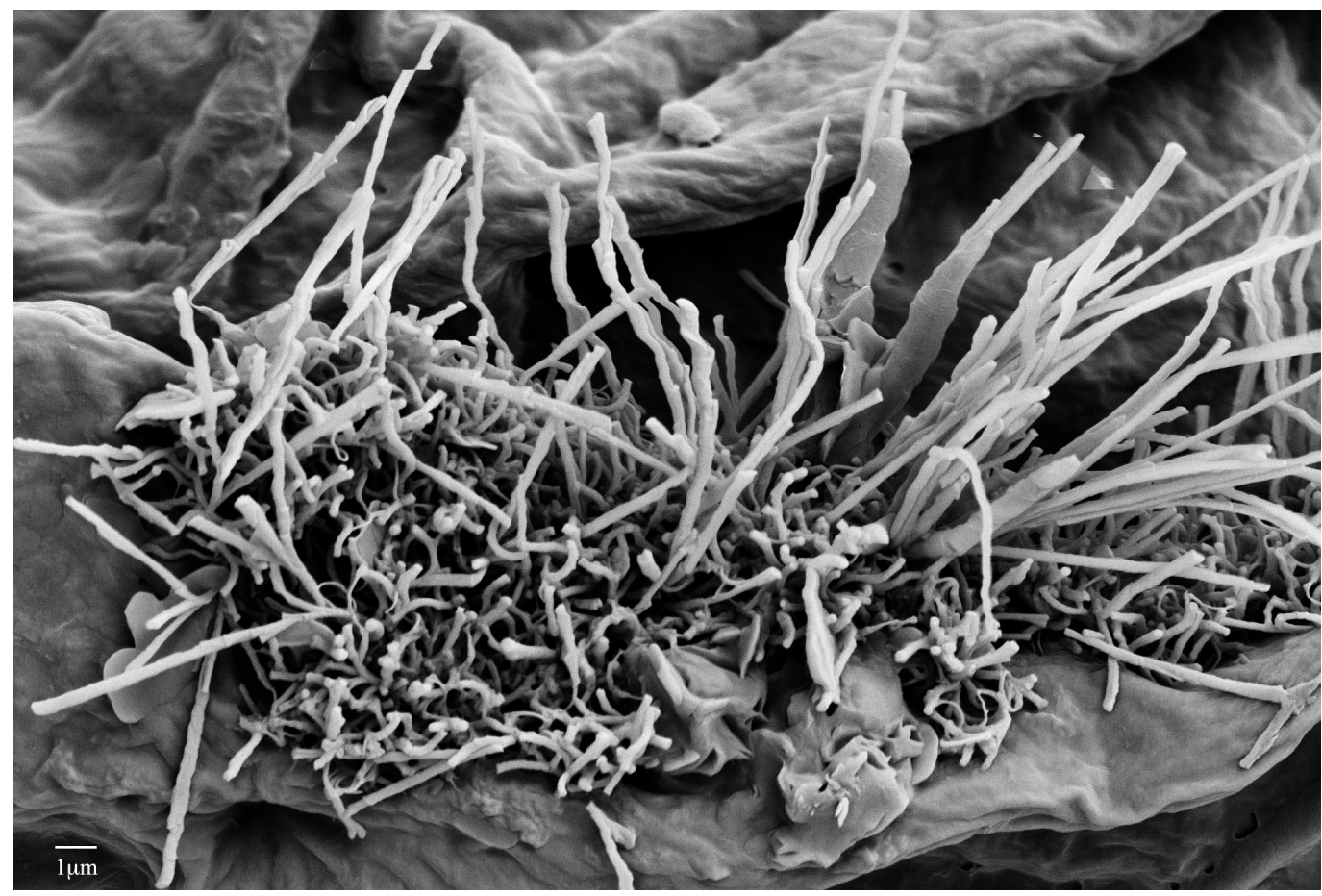

Figure 2. Waxy deposits on the surface of Vaccinium ceraceum [Kato et al. 23426 (E)]. Magnification: $\times$ 7500. Scanning electron micrograph: F. Christie. Reproduced from Argent (2018) with the permission of the Trustees of the Royal Botanic Garden Edinburgh.

(Chu et al., 2017). Notably, this wax has been found on a species from New Guinea, which is phytogeographically distant from the locality in Borneo where the first Southeast Asian record occurred. No known species of Vaccinium are common to Borneo and New Guinea.

Published genus-wide phylogenetic studies of the relationships between the infrageneric groupings in Vaccinium, for example that by Kron (2002), were based on limited sampling ( $<10 \%$ of species) and did not include V. ceraceum or V. brassii. Therefore, it is impossible to state with confidence whether or not the two species are closely related. On morphological evidence, they are not. Sleumer (1966-1967) placed Vaccinium brassii in Vaccinium sect. Bracteata Nakai, and Argent (2018), following Sleumer, placed V. ceraceum in the same section.

Vander Kloet \& Dickinson (2009) drastically changed the circumscription of Vaccinium sect. Bracteata but without support from molecular data. In their interpretation of the sections, Vaccinium brassii would probably be in Vaccinium sect. Nesococcus H.F.Copel., in which Sleumer had placed it in his earlier treatment (Sleumer, 1961). In the absence of reliable molecular data from a more representative sample of the c. 440 species of Vaccinium, it is difficult to specify the relationship between the two species considered in this paper. 
Woods' specimen must have been dried slowly under gentle heat, because subsequent investigation with the scanning electron microscope revealed the scurfy deposits to be tufts of filamentous wax (Figures 3,4 ). Superficial wax such as this has not been observed on the flowers of any other Malesian species in cultivation at the Royal Botanic Garden Edinburgh (RBGE).

As with Vaccinium ceraceum, the wax could not have been a chemical artefact of specimen processing because the deposits were restricted to the floral parts and did not occur on the leaves or stems. When boiled in detergent, they dissolved and were no longer visible.

Further surveys of living material or herbarium material that is known not to have been in contact with alcohol will reveal whether similar wax structures occur more widely in the genus.

\section{Acknowledgements}

The RBGE is supported by the Scottish Government's Rural and Environment Science and Analytical Services Division. The senior author is grateful to the RBGE for continued use of its research facilities. F.C. is grateful for the assistance of Dr Mark Newman in the preparation of the final version of this paper.

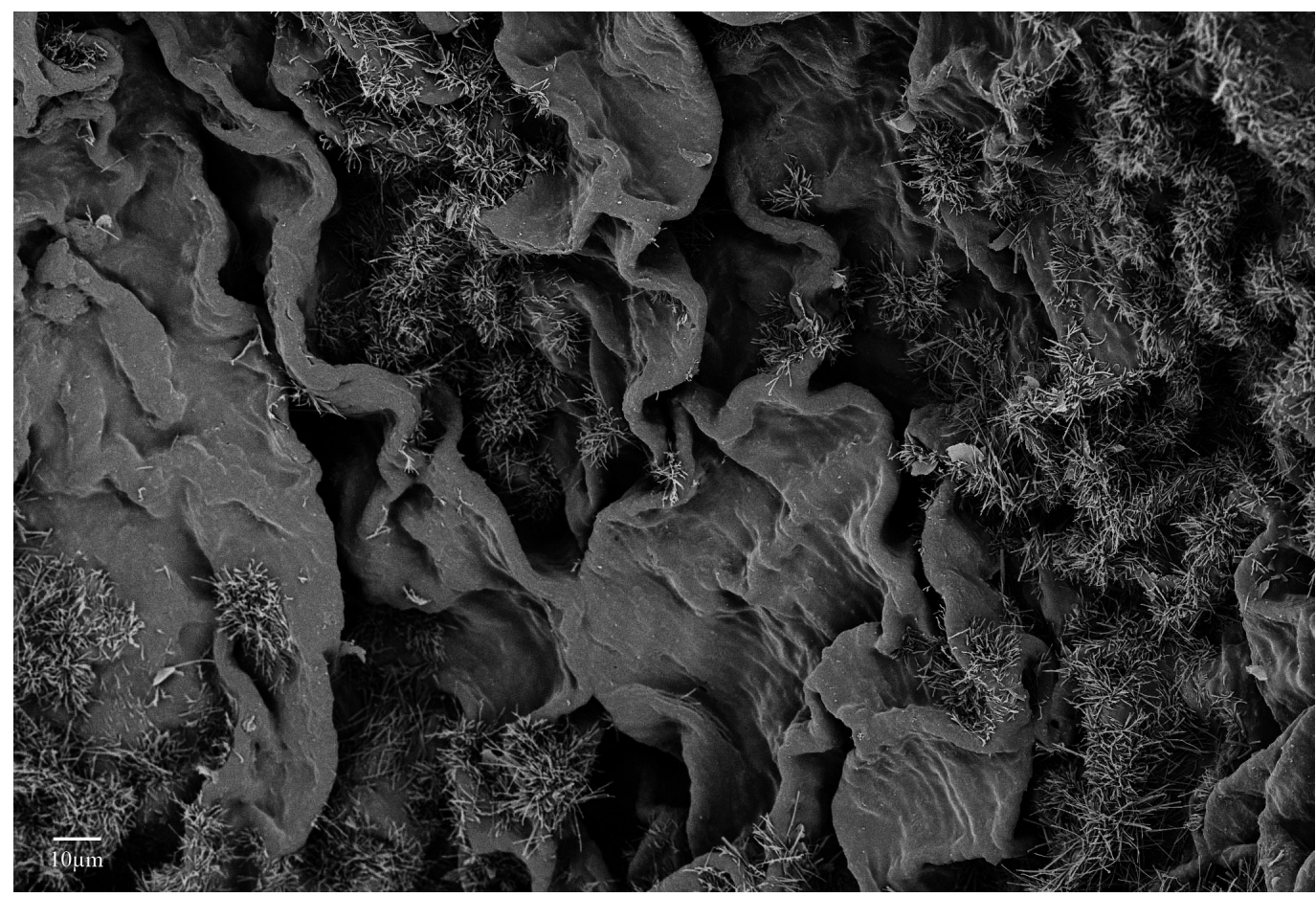

Figure 3. Waxy deposits on the surface of the corolla tube of Vaccinium brassii [Woods 3039 (E)]. Magnification: $\times$ 400. Scanning electron micrograph: F. Christie. 


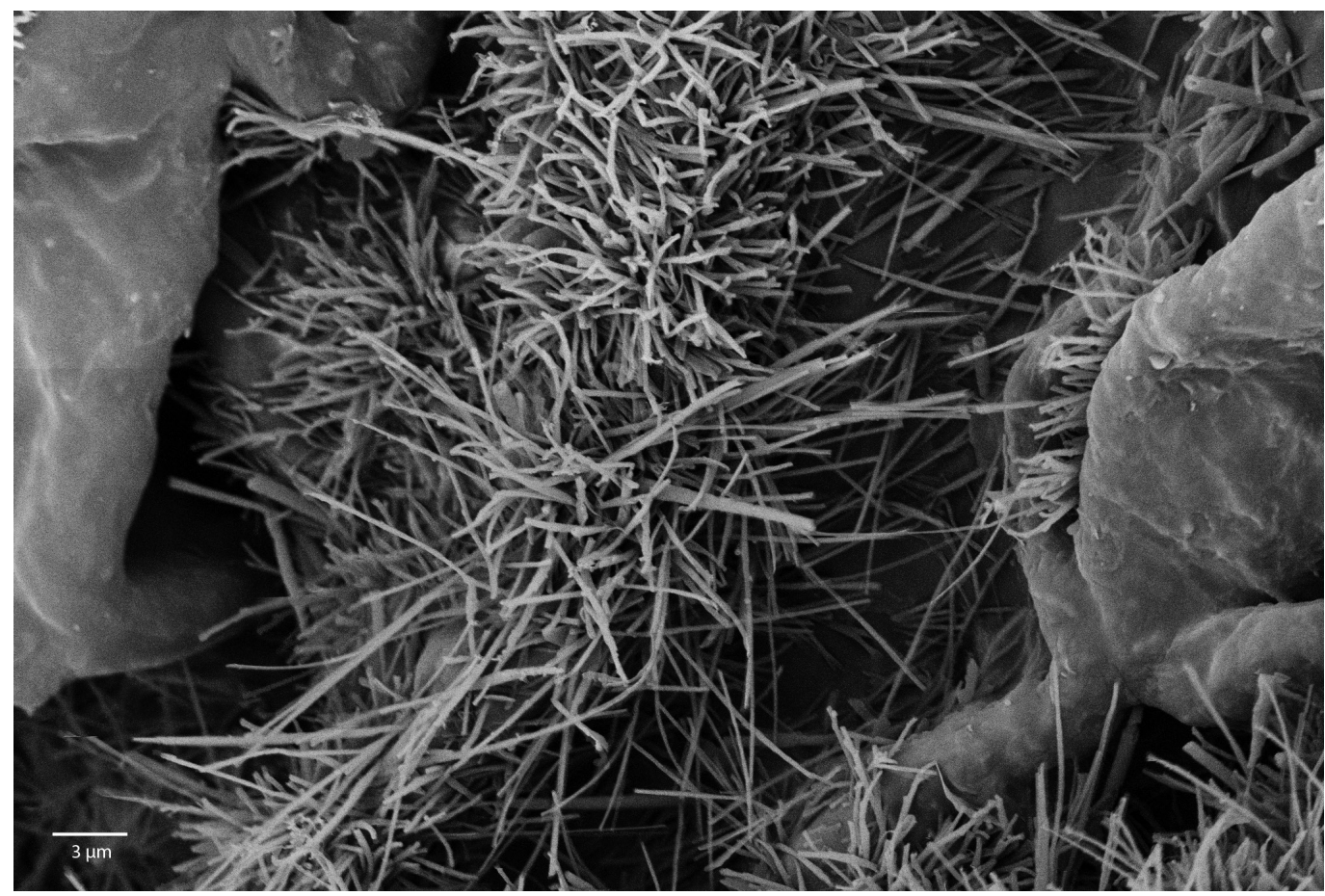

Figure 4. Waxy deposits on the surface of the corolla tube of Vaccinium brassii [Woods 3039 (E)]. Magnification: $\times 2000$. Scanning electron micrograph: F. Christie.

\section{A note on the preparation of this paper}

The submitted version of this paper had just been reviewed when news came of the death of George Argent on 24 April 2019. As the Associate Editor to which it had been assigned, I was about to send the reviewers' comments to George on that day so that he could finalise the manuscript for publication. This is the last article he submitted, so it seemed only proper that I should help Frieda Christie get it published in George's memory.

Mark Newman

\section{References}

Argent G. 2018. Rigiolepis and Vaccinium (Ericaceae) in Borneo. Edinburgh Journal of Botany. 76(1):55-172.

Chu WJ, Gao HY, Cao SF, Fang XJ, Chen HJ, Xiao SY. 2017. Composition and morphology of cuticular wax in blueberry (Vaccinium spp.) fruits. Food Chemistry. 219:436-442.

Kron KA, Powell EA, Luteyn JL. 2002. Phylogenetic relationships within the blueberry tribe (Vaccinieae, Ericaceae) based on sequence data from matK and nuclear ribosomal ITS regions, with comments on the placement of Satyria. American Journal of Botany. 89(2):327-336. 
Sleumer HO. 1942. Revision der Ericaceen von Neu-Guinea 2. Botanische Jahrbücher für Systematik, Pflanzengeschichte und Pflanzengeographie. 72:207-269.

Sleumer HO. 1961. Florae Malesianae Precursores XXVIII. The genus Vaccinium in Malesia. Blumea. 11(1):9-112.

Sleumer HO. 1966-1967. Ericaceae. In: Van Steenis CGGJ, editor. Flora Malesiana, Series 1: Spermatophyta (Seed Plants), vol. 6. Groningen: Wolters-Nordhoff. pp. 669-914.

Vander Kloet SP, Dickinson TA. 2009. A subgeneric classification of the genus Vaccinium and the metamorphosis of $V$. section Bracteata Nakai: more terrestrial and less epiphytic in habit, more continental and less insular in distribution. Journal of Plant Research. 122(3):253-268. 